\title{
Um olhar informacional para os mundos cultuais da internet
}

\begin{abstract}
Héctor René Mena Méndez Mestrando em Ciência da Informação pelo Programa de Pós-Graduação em Ciência da Informação da Escola de Comunicações e Artes da Universidade de São Paulo - ECA/USP, Brasil

E-mail: $\underline{\text { hmena @usp.br }}$
\end{abstract}

KOZINETS, Robert V. Netnografia: realizando pesquisa etnográfica online. Porto Alegre: Penso, 2014. ISBN 978-85-65848-97-8.

Considere o exemplo de Samanta. Animada pela sua próxima viagem à Agra, Índia, a intrépida jovem mochileira está procurando informações "confiáveis" no Google; clicando no link da Wikipédia, e depois visitando o website oficial de Agra, ela começa a descobrir e visitar websites que apresentam informações de "terceiros", informações de outras "pessoas reais", exceto que essas pessoas de fato já estiveram onde ela deseja ir. Nesse contexto, Samanta começa a interagir em um fórum. Uma de suas respostas é considerada culturalmente insensível e ofensiva por um dos membros que regularmente publica no grupo - e que casualmente é indiano -; aquela pessoa insulta a Samanta publicamente, mas outro membro, um líder no grupo, defende-a gentilmente e sugere que ela se desculpe; a jovem, apesar de seu profundo constrangimento, pede desculpas. Ela pensa em jamais voltar...

A experiência de Samanta, que deixaremos aqui como inconclusa, parece exemplar para refletir sobre os desafios que a internet tem representado nos diferentes campos do conhecimento, com especial ênfase na Ciência da Informação, considerando as estruturações da ordem tradicional na lógica de produzir, disseminar e usar a informação e o conhecimento. Como vimos no exemplo, informações baseadas em fatos são aprendidas em paralelo com o conhecimento da linguagem especializada da comunidade online e com conceitos sensíveis, normas, valores, rituais, práticas, preferências e identidades de especialistas e outros membros do grupo. O que se iniciou basicamente como uma busca de informações se transforma em uma fonte de comunhão e compreensão; pelo menos assim o considera o professor canadense, Robert Kozinets, em seu livro Netnografia: realizando pesquisa etnográfica online, recentemente traduzido para o português e lançado no Brasil em 2014. 
Como pesquisador na área de marketing na York University, em Toronto, Canadá, Kozinets tem desenvolvido, há mais de dez anos, um número significativo de pesquisas com base na abordagem metodológica netnográfica, considerada uma forma especializada de etnografia, que traspõe a discussão das experiências sociais face a face para as experiências da mediação, sociabilidade e apropriação social das Tecnologias da Informação e da Comunicação (TIC), dentro de uma comunidade ou cultura digital em particular. Apesar de que o professor acentua o fato da netnografia tem surgido em estudos sobre marketing e consumo, reconhece, também, que o termo tem alcançado certa maturidade pelo uso e incorporação em diferentes campos das ciências sociais.

Não resta dúvida, insistirá Kozinets, que os novos estudos sobre o uso da internet e outras tecnologias de informação e comunicação estão contribuindo significativamente para a literatura de estudos culturais, sociologia, economia, direito, ciência da informação ${ }^{1}$, áreas de negócios e administração, estudos da comunicação, geografia humana, enfermagem e assistência médica e antropologia. Essas disciplinas formaram seus entendimentos específicos do trabalho relacionado de estudiosos atuantes em outros campos teóricos.

De fato, de acordo com o autor, os cientistas sociais chegam cada vez mais à conclusão de que não podem mais compreender adequadamente muitas das facetas da vida social e cultural sem incorporar a internet e as comunicações mediadas por computador em seus estudos. Para fundamentar essa teoria, no caso da Ciência da Informação, por exemplo, se parte do pressuposto de que os usuários - entendidos na área como indivíduos que se valem e que usam a informação para o desenvolvimento de suas atividades pessoais, como para a solução de problemas específicos - se posicionam de forma ativa e dinâmica nos ambientes digitais da internet, reconfigurando a lógica tradicional do emissor/mensagem/receptor na estrutura do sistema comunicacional.

Contudo, Kozinets questiona as diversas conotações que termo vem adotando segundo as necessidades de cada área. Assim, as ciências econômicas e empresariais se inclinam pela concepção de netnografia; já na linha mais antropológica e das ciências sociais, pode-se encontrar o uso de "etnografia virtual". O professor canadense considera estéril a discussão do neologismo, mas concorda na necessidade de se adotar uma nomenclatura que venha a

\footnotetext{
${ }^{1}$ No caso específico da Ciência da Informação no Brasil, destacam-se algumas pesquisas como o estudo dos hábitos e comportamentos dos usuários que visitam a Biblioteca Digital de Teses e Dissertações (PINTO et al., 2007) ou o estudo acerca das mediações da informação através da comunidade virtual Anobii (CRIPPA; CARVALHO, 2012).
} 
especificar as diferenças existentes entre uma etnografia online e aquela offline. Sob essa necessidade por desdobrar outros procedimentos específicos para o estudo das culturas e comunidades digitais, o autor assinala os seguintes pontos:

Primeiro, o ingresso na cultura ou comunidade online é diferente. Ele diverge do
termo face a face em termo de acessibilidade, abordagem e extensão da potencial
inclusão. "Participação" pode significar algo diferente pessoalmente do que online.
Assim como o termo "observação". Segundo, a coleta e análise de dados culturais
apresentam determinados desafios bem como oportunidades que são novas. A
ideia de "inscrição" de "notas de campo" é radicalmente alterada. As quantidades de
dados podem ser diferentes. A capacidade de aplicar determinados instrumentos e
técnicas analíticas muda quando os dados já estão em formato digital. O modo como
os dados precisam ser tratados pode ser diferente. Finalmente, existem poucos ou
nenhum procedimento ético para o trabalho de campo realizado pessoalmente
que se traduzam facilmente para o meio online. As diretrizes abstratas do
consentimento informado estão sujeitas a amplos graus de interpretação (KOZINETS,
2014, p. 13).

Esses procedimentos são aprofundados no primeiro capítulo do livro ao se justificar o porquê da conformação de comunidades e culturas online, além da sua importância nos estudos das ciências sociais no último século. Em 1996, nos lembra o autor, havia aproximadamente 250 mil websites oferecendo conteúdo publicado a um universo aproximado de 45 milhões de usuários, localizados principalmente na América do Norte e na Europa Ocidental. Em 2009, o número de usuários da internet ao redor do mundo ultrapassou 1,5 bilhão, o que corresponde a $22 \%$ da população mundial. Não é por acaso, portanto, a implementação de um grupo vasto de netnografias $^{2}$, em torno a uma ampla variedade de temas, durante a última década. Nos próximos dois capítulos se analisa, de maneira concreta, alguns desses estudos, a fim de ter uma visão geral dos processos culturais e os rituais que caracterizam a uma comunidade digital, assim como os métodos utilizados para compreender esses fenômenos.

A essência do livro: apresentar um conjunto rigoroso de diretrizes para a realização de etnografias mediadas pelos ambientes digitais da internet, se concentra nos capítulos 4, 5, 6, 7, e 8 , a descrever, cada um deles, uma das etapas que caracteriza a abordagem qualitativa da netnografia. Numa perspectiva de síntese, Kozinets considera cinco etapas para o desenvolvimento do método: a primeira, entrée cultura, que consiste na identificação do objeto de pesquisa; a segunda, a coleta de dados, limitada à aquisição dos dados na comunidade virtual do estudo; a terceira, a análise e interpretação, fundamentada na classificação,

\footnotetext{
${ }^{2}$ Estudos netnográficos foram usados para estudar a ética mundial e as percepções de compartilhamento direto de arquivos (COHN; VACCARO, 2006), investigar o ativismo dos consumidores (KOZINETS; HANDELMAN, 1998) e mostrar como a criação e aprendizagem do conhecimento ocorrem mediante um discurso reflexivo de "reexperimentação virtual" entre os integrantes de comunidades eletrônicas inovadoras (HEMETSBERGER; REINHARDT, 2006)
} 
codificação e contextualização dos dados; a quarta, concernente à ética informacional no uso dos dados patrocinados pelos indivíduos pesquisados e, por último, a etapa da validação, onde se compara a teoria desenvolvida com a comunidade ou cultura pesquisada.

A ética informacional pode ser uma das categorias com maior importância no debate etnografia tradicional versus etnografia online; o tema, por sua vez, se posiciona de maneira significativa para a grade curricular científica e técnica da Ciência da Informação, dada a universalidade, velocidade e intensidade que caracteriza o contexto contemporâneo. Assim, as questões éticas sobre a netnografia giram em torno de aspectos paradoxais e tensionados; o caso de se os fóruns electrónicos devem ser considerados um local público ou privado; "o que acontece quando uma geração inteira realiza grande parte de sua socialização online e construção de comunidades por meio de websites comerciais como Facebook?” (p. 164) Ou questões ligadas à produção e disseminação de informações de natureza autoral, elencando os debates de acesso e liberdade de informação.

Nos capítulos finais do livro, Kozinets se dedica a discutir algumas das mudanças e os avanços na abordagem metodológica, com objeto de refletir acerca das oportunidades - e ameaças - que representa o estudo dos ambientes e comunidades online para cristalizar, de maneira mais consistente, o trabalho desenvolvido nestas três décadas de pesquisa netnográfica."A tarefa do netnógrafo é ser tanto explorador quanto cartógrafo desse novo e empolgante terreno cultural, um explorador que estuda de maneira respeitosa e minuciosa as pessoas que surgem rapidamente para habitar e colonizar esses novos mundos virtuais." (p. 166)

Em resumo, estimular o pensamento para ir além do conhecido, a partir do estudo de experiências e casos concretos, considerando as diferentes opções que os pesquisadores dispõem para analisar os mundos culturais da internet, é o principal desafio que se coloca Robert Kozinets no seu livro pioneiro da netnografia. Sob essa perspectiva, a abordagem netnográfica seria concebida não como um método já estabelecido, mas em processo de construção e produção, sendo, portanto, vislumbrada como uma técnica metodológica que encontra na atividade dos seus pesquisadores a definição do seu conteúdo e contexto social. 


\section{Referências}

COHN, D.; VACCARO, V. L. A study of neutralisation theory's application to global consumer ethics: $\mathrm{p} 2 \mathrm{p}$ file-trading of musical intellectual property on the internet,

International Journal of Internet Marketing and Advertising, v. 3, n. 1, p. 68-88, 2006.

CRIPPA, G.; CARVALHO, L. A. A mediação da informação através da comunidade virtual Anobbi: um estudo de caso. Encontros Bibli: Revista Eletrônica de Biblioteconomia e Ciência da Informação, v. 17, n. 35, p. 97-120, set./dez., 2012.

HEMETSBERGER, A.; REINHARDT, C. Learning and knowledge-building in open-source Communities: a social-experiential approach. Management Learning, v. 37, n. 2, p. 187$214,2006$.

KOZINETS, R.; HANDELMAN, J. M. Ensouling consumption: a netnographic exploration of the meaning of boycotting behavior. In: ALBA, J.; HUTCHINSON, W. (Ed.). Advances in Consumer Research, v. 25, p. 475-88, 1998.

PINTO, V. B. et al. "Netnografia": uma abordagem para estudos de usuários no ciberespaço. Actas do Congresso Nacional de Bibliotecários, Arquivistas e Documentalistas, Ponta Delgada, n. 9. 2007. 